\title{
IDENTITAS ORANG SASAK: \\ STUDI EPISTEMOLOGIS TERHADAP MEKANISME PRODUKSI PENGETAHUAN MASYARAKAT SUKU SASAK
}

\author{
Dedy Wahyudin \\ Prodi Bahasa Arab FTK Universitas Negeri Mataram \\ e-mail: dewasa2008@gmail.com
}

\begin{abstract}
Abstraks: Artikel ini hendak menjawab dua persoalan krusial terkait identitas orang Sasak: pertama, apakah inti identitas orang Sasak sekaligus unsur-unsur pembentuknya; kedua, bagaimana mekanisme pengetahuan dan perilaku pada masyarakat Sasak. Jawaban dari dua soal ini sangat penting sebagai pijakan suku bangsa Sasak untuk meraih masa depan yang lebih baik. Penelitian dilakukan dengan pendekatan kualitatif berjenis penelitian fenomenologis. Penelitian jenis fenomenologis paling cocok untuk tema penelitian tentang identitas ditambah lagi dengan kenyataan bahwa peneliti adalah orang Sasak yang tentu saja menyerap dan merasakan sendiri menjadi orang Sasak. Hasil penelitian menunjukkan bahwa inti identitas orang Sasak adalah agama dan adat atau Islam dan tradisi. Tradisi Sasak merupakan pengejawantahan dari ajaranajaran Islam yang selanjutnya membentuk perilaku yang tipikal bagi masyarakat Sasak yaitu menjadi muslim taat yang berbudaya tinggi pada saat yang sama.
\end{abstract}

Kata Kunci: identitas, agama, budaya, tradisi, pengetahuan, perilaku

Title: The Identity of Sasak People: Epistemology Study to the Mechanism of Knowledge Production of Sasak Tribe Community

Author: Dedy Wahyudin

Abstract: This article will answer two crucial issues related to the identity of Sasak people: first, what are the core identities of the Sasak people and the forming elements?, second, how are the mechanisms of knowledge and behavior in the Sasak community?. The answers to these two questions are very important as a foothold of the Sasak ethnic group to achieve the better future. The research was conducted with a qualitative approach of the type of phenomenological research. The research of the phenomenological type is best suited to the theme of identity research added to the fact that researcher is Sasak person who naturally absorb and feel himself as person of Sasak. The results of the research showed that the core identity of the Sasak people is religion and custom or Islam and tradition. The Sasak tradition is an embodiment of Islamic ideologies which further form a typical behavior for the Sasak community, namely: being a loyal Muslims and they have bigh culture at the same time.

Keywords: identity, religion, culture, tradition, knowledge, behavior 


\section{Pendahuluan}

Mengapa mesti mempertanyakan identitas orang Sasak? Apa konteks sejarahnya? Bukankah pertanyaan soal identitas seharusnya sudah selesai? Bukankah kehidupan masyarakat Sasak sejauh ini berjalan baik-baik saja? Bukankah tidak ada hal luar biasa yang mengharuskan pembongkaran identitas mereka? Pertanyaan-pertanyaan senada muncul di kalangan para pemikir Eropa abad pencerahan. Hal yang sama muncul di kalangan para pemikir Arab pasca kolonialisme terutama sejak tragedi 1967. Pada konteks Indonesia, Mochtar Lubis misalnya, pada tahun 1977 mempertanyakan siapa sebenarnya manusia Indonesia itu. Benang merahnya adalah setiap kali ada tantangan sejarah yang kemudian disambut oleh kegelisahan para intelektual, ketika itulah pertanyaan tentang identitas menemukan justifikasinya.

Badai perubahan itu kini betul-betul tidak bisa lagi dielakkan. Seseorang sudah tidak bisa lagi memilih menjadi modern atau tradisional ketika alat-alat produksi modernitas menempel sampai relung-relung terdalam kehidupan manusia; tidak bisa lagi memilih menjadi global atau lokal ketika batas-batas wilayah negara, daerah, komunitas atau bahkan individu runtuh dimana-mana; tidak lagi bisa memilih masuk atau keluar dari dunia revolusi informasi dan telekomunikasi ketika yang nyata dan yang maya tumpang tindih di pelataran kesadaran setiap orang.

Dalam kondisi semacam ini, gegar identitas pun terjadi. Pilihan yang segera muncul ke permukaan, satu di antara tiga: melebur dengan identitas yang kuat, yang menang bahkan yang menjajah; keluar dari percaturan dengan romantisme ke masa lalu dan memeluk kuat identitas lama yang tidak lagi kompatibel dengan perubahan zaman; atau mengkonstruksi ulang identitas berbasis masa lalu dengan kehendak kuat untuk menyongsong masa dengan dengan identitas baru agar tetap eksis dalam pergaulan antar bangsa, antar komunitas.

Pertanyaan tentang masa depan orang Sasak adalah - pertama kali-pertanyaan tentang identitasnya. Selama pembongkaran dan penyusunan ulang identitas tidak dilakukan, maka masa depan orang Sasak tidak akan pernah berpijak di atas kaki-kaki yang kuat. Untuk itulah penelitian tentang apa sesunggunya identitas orang Sasak, bagaimana produksi pengetahuan dilakukan, bagaimana tindakan dibentuk berdasarkan pengetahuan itu penting dilakukan agar masyarakat Sasak bisa menyambut tantangan perubahan sejarah dengan gagah dan meraih masa depan yang indah dengan senyum sumringah.

Fokus tulisan ini kemudian adalah: Apakah inti identitas orang Sasak itu? Apakah unsurunsur pembentuknya?; Bagaimanakah mekanisme produksi pengetahuan dan perilaku dalam masyarakat Sasak? 


\section{Metode Penelitian}

Penelitian dilakukan dengan pendekatan kualitatif berjenis penelitian fenomenologis. Penelitian jenis fenomenologis paling cocok untuk tema penelitian tentang identitas ditambah lagi dengan kenyataan bahwa peneliti adalah orang Sasak yang tentu saja menyerap dan merasakan sendiri menjadi orang Sasak. Karena itu, dalam penelitian ini akan lebih banyak menggunakan wawancara mendalam pada sumber-sumber primer. Selain itu, juga peneliti akan menggunakan observasi partisipasi langsung sebagai salah satu cara memahami fenomena yang diteliti. Penelitian ini difokuskan pada orang Sasak di wilayah Nusa Tengara Barat (NTB).

\section{Hasil Penelitian dan Pembahasan \\ Identitas Orang Sasak}

Sejarah orang Sasak adalah sejarah kolonialisme, hegemoni atau --paling tidakdominasi. Pemerintahan dari, oleh dan untuk orang Sasak belum penah betul-betul terjadi, kecuali dalam waktu sekitar dua dasawarsa terakhir. Pergantian kekuasaan dari waktu ke waktu dalam rentang sejarah yang panjang di masyarakat Sasak terjadi dari satu outsider ke outsider yang lain.

Memang benar, banyak kerajaan pernah eksis di Gumi Sasak namun sejarah kerajaankerajaan itu adalah sejarah konflik, intrik politik dan --berujung pada-- pendudukan oleh kekuatan-kekuatan luar, mulai dari Majapahit, Makassar/Gowa, Karangasem, Belanda dan Jepang. Setelah Indonesia merdeka sekalipun, tampuk pemerintahan masih juga dipegang oleh outsider hingga pada Tahun 2003, H.L. Serinata tercatat sebagai orang Sasak pertama yang menjadi Gubernur Nusa Tenggara Barat. ${ }^{1}$

Interaksi insiders (orang Sasak) dengan ousiders (orang non Sasak) telah meninggalkan jejak yang sudah membaur ke dalam relung-relung yang sangat dalam yang membentuk identitas orang Sasak yang terlihat saat ini. Jejak-jejak itu menjadi sangat sulit bahkan mustahil untuk dipilah kembali karena akumulasi waktu dan peristiwa telah membentuk formasi orang Sasak yang di dalam dirinya ada kegetiran, intervensi, infiltrasi, keterberaian, keberterimaan, keberdamaian dengan keadaan, refleksi, kesadaran dan optimisme menatap masa depan betapapun sulit dan menantangnya.

Bauran faktor kesejarahan inilah yang kelak menjadi salah satu pembentuk kekhasan identitas orang Sasak. Pengalaman getir penjajahan/penaklukan berulang-ulang dialami bangsa Sasak sejak abad ke-14. Tahun 1357, Lombok jatuh di bawah kekuasaan Kerajaan Majapahit. Tahun 1672, Kerajaan Selaparang luluh lantak diserbu pasukan Kerajaan Karangasem. Tahun 1908, wilayah Bali dan Lombok sepenuhnya sudah jatuh ke tangan

${ }^{1}$ http://www.sasak.org/2009/05/gubernur-sasak-ntb-antara-harapan-dan-realita/, diakses Tanggal 1 November 2017, Jam 19.00 WITA. 
penjajah Belanda. Tahun 1942, Jepang mengakhiri penjajahan Belanda dan menjadi penjajah baru di gumi Sasak.

Orang Sasak menyebut tanah air dengan istilah gumi paer. Dalam bahasa Kawi-Jawa, gumi artinya bumi; dan paer berasal dari kata pabyaran-panggenan yang berarti tempat tinggal. "Sebagai tempat tinggal, paèrtidak hanya semata alamat dengan nomor tertentu, tetapi di dalamnya termasuk juga tempat lahir, tempat bersama keluarga, kampung halaman dan komunitas, dan secara implisit menyangkut istiadat serta tradisi.". ${ }^{2}$

Dalam konsep seperti ini, paer bukan sekedar urusan tata ruang, geogarafis-kosmologis, tetapi juga geosimbolis-geososiologis. ${ }^{3}$ Selanjutnya, paer dalam masyarakat Sasak terbagi menjadi paer timuq, paer baret, paer lauq, paer daye dan paer tengaq. Secara struktural, di bawah gumi paer ada dese paer, gubuk gempeng dan bale langgaq. Seluruh struktur lokus ini terikat dengan berbagai pranata nilai dan pemangku-nya sehingga totalitas keterkaitan lokus, nilai dan spirit dijaga mulai dari tingkat terbawah sampai tingat gumi paer.

Dengan demikian, "gumi paèr merupakan rumusan simbolik tentang jagat raya seisinya, ekosistem, yang berinteraksi dengan tiga konsep lingkungan artifisial manusia Sasak. Ketiga lingkungan itu, ialah lingkungan material, lingkungan sosial, dan lingkungan simbolik. Yang dimaksud dengan lingkungan material adalah rumah, sawah, jalan, peralatan-peralatan dan sebagainya. Lingkungan sosial ialah organisasi sosial, stratifikasi, sosialisasi, gaya hidup, dan sebagainya. Lingkungan simbolik ialah segala sesuatu yang meliputi makna dan komunikasi, seperti kata, bahasa, agama/kepercayaan, ilmu, mite, nyanyian, seni, upacara, tingkah-laku, benda-benda, konsep-konsep, dan sebagainya". ${ }^{4}$

Luas Pulau Lombok kurang lebih $5435 \mathrm{Km}^{2} .5$ Banyak wisatawan mengatakan bahwa Lombok adalah sepotong surga di muka bumi. ${ }^{6}$ Pernyataan ini pasti merujuk kepada keindahan alam Pulau Lombok. Dalam sebuah kesempatan, Kepala Dinas Pariwisata NTB, L.M. Faozal mengatakan bahwa Lombok memiliki semua yang ingin orang kunjungi menyangkut alam, mulai dari ketinggian puncak gunung sampai keanekaragaman hayati bawah laut. ${ }^{7}$ Tidak heran, Lombok kini tengah dan terus akan diproyeksikan sebagai destinasi wisata kelas dunia. Gumi paer Sasak itu memang sangat kaya dengan keindahan alam.

2 http://www.suararevolusi.com/2015/10/pola-pembangunan-wisata-di-kabupaten.html, diakses Tanggal 3 Nov 2017, Jam 06.45 WITA.

${ }^{3}$ Ibid.

${ }^{4}$ Ibid.

${ }^{5}$ http:/ / www.wacana.co/2010/07/sejarah-dan-tradisi-suku-sasak/, diakses Tanggal 3 Nov 2017, Jam 16.30 WITA.

${ }^{6}$ http:/ / www republika.co.id/berita/gaya-hidup/travelling/16/01/21/o1aa6y361-sepotong-surga-dipulau-lombok, diakses Tanggal 3 Nov 2017, Jam 17.00 WITA.

${ }^{7}$ Disampaikan di acara Seminar Bahasa Arab dan Pariwisata Halal oleh HMJ PBA FTK UIN Mataram, Sabtu, 5 November 2017. 
Gumi paer Sasak itu ditinggali oleh masyarakat Sasak yang sekitar $80 \%$ beragama Islam, $15 \%$ Hindu (sebagian besar dulunya berasal dari Bali), sisanya pemeluk agama lain dari berbagai etnis selain tersebut di atas. ${ }^{8}$ Komposisi ini terjadi setelah perjalanan agama-agama dalam lintasan sejarah timbul dan tenggelam mulai dari agama "boda", Hindu-Budha dan kemudian Islam.

Islam masuk ke Lombok melalui dua jalur, yaitu dari barat (Jawa) dan dari timur (Gowa). ${ }^{9}$ Dari sumber Jawa, nama yang sering disebut adalah Sunan Prapen atau Pangeran Prapen. Ada dua versi tentang jalur penyebaran Islam yang dilakukan oleh tokoh ini: pertama, melalui ekspedisi militer ke Lombok di Tahun 1545; dan kedua, segera setelah menaklukan Kerajaan Majapatih-Hindu, penguasa Islam di Jawa, mengirim sunan Prapen utusan ke Lombok dan Sumbawa untuk menyebarkan Islam. Utusan ini pertama kali berlabuh di Labuan Carik yang sekarang dikenal dengan Bayan di utara Pulau Lombok. ${ }^{10}$ Sementara itu, "Pada abad ke- 17 seluruh Kerajaan Islam Lombok berada di bawah pengaruh kekuasaan Kerajaan Gowa. Hubungan antara Kerajaan Gowa dan Lombok dipererat dengan cara perkawinan seperti Pemban Selaparang, Pemban Pejanggik, dan Pemban Parwa". ${ }^{11}$ Inilah yang menjelaskan dua jalur masuknya Islam ke Pulau Lombok.

Suku Sasak meyakini bahwa agama dan adat sama-sama bisa berjalan tanpa yang satu menafikan yang lain. Lebih dari itu, pranata adat dengan segala simbol yang dimiliki adalah bentuk pengejawantahan dari ajaran agama (Islam dalam hal ini). Sistem nilai dalam budaya Sasak terdiri dari tiga lapis: lapis terdalam adalah nilai-nilai dasar/filosofis, lapis kedua adalah penyangga moral dan lapis ketiga adalah simbol aplikatif dari dua lapis sebelumnya. ${ }^{12}$

Di lapis pertama ada nilai tindih yang memotivasi orang Sasak untuk menjadi manusia yang patut (benar), patuh (taat), pacu (rajin), solah (baik) dan soleb (saleh, damai). Di lapis kedua, ada nilai maliq (larangan, tidak boleh) dan merang (semangat berbuat baik dan positif). Sedangkan di lapis ketiga, praktik kolektif untuk membangun kebaikan berasama seperti sangkep (musyawarah) dan lain-lain. ${ }^{13}$

Pada lapis ketiga ini pulaa dikenal istilah krame (norma) dan awig-awig (aturan) yang digunakan oleh masyarakat Sasak untuk mengatur kehidupan bersama dalam harmoni. Dalam krame, ada tiga krame yaitu titi krame, base krame dan aji krame. Titi krame menyangkut

8 https://id.wikipedia.org/wiki/Pulau_Lombok, diakses Tanggal 5 November 2017,Jam 08.30 WITA..

${ }^{9}$ Fadjal AR Bafadhal dan Asep Saefullah. Naskah Klasike Keagamaan Nusantara Cerminan Budaya Bangsa 1. Jakarta: Puslitbang Lektur Keagamaan Departemen Agama RI, 2005., h. 15.

${ }_{10}$ Asnawi. Respons Kultural Masyarakat Sasak Terbadap Islam. Jurnal Ulumuna IAIN Mataram, Vol IX Edisi 15, No 1, Januari-Juni 2005, h. 4-5.

11 http:/ / www.kuttabku.com/2017/01/sejarah-kerajaan-islam-atau-kesultanan-selaparang-lombok-danbima-di-nusa-tenggara.html, diakses Tanggal 5 November 2017, Jam 11.30 WITA.

12 Sabirin. Konfigurasi Pemikiran Islam Tuan Guru: Respon Pemikiran Tuan Guru Terbadap Penetrasi Ajaran Wababi pada Etnik Sasak di Pulau Lombok 1993-2007. Tesis. Program Pascasarjana UI, 2008, h. 25-26.

${ }_{13}$ Ibid. 
aturan midang (berkunjung ke rumah pacar) dan betemue (bertamu). Base kerame adalah bahasa tubuh dan lisan yang harus dilakukan dengan tertib-tapsila (sopan). Sedangkan aji krame menyangkut harga kehormatan seseorang yang biasanya dilakukan dalam prosesi pernikahan yang disebut sorong serah aji krame. ${ }^{14}$

Dalam sejarah-nya, masyarakat mengenal stratifikasi sosial berbasis jauh-dekat-nya dengan raja dan keluarga kerajaan. Tingkatannya tersusun menjadi tiga: tingkat tertinggi ningrat atau perwangse (bangsawan kelas satu), di tengah ada triwangse (bangsawan kelas dua) dan tingkat terendah disebut jajar karang (orang biasa). Dua golongan pertama disebut permenak atau menak. ${ }^{15}$

Strata sosial ini bisa dipastikan adalah warisan zaman kerajaan-kerajaan yang pernah eksis di Lombok dengan latar budaya dan agama Hindu yang terkenal dengan sistem kastanya. Jika pada masanya, pelapisan sosial ini bekerja efektif dalam seluruh sistem sosial yang bekerja di masyarakat, kini pelapisan itu tidak lagi ketat dan kaku sebagaimana zaman dahulu. Sedikit saja yang masih tersisa, seperti gelar/sebutan di depan nama dan prosesi pada adat pernikahan. Selebihnya, acuan-acuan posisi sosial sudah banyak bergeser searah perubahan zaman yang sudah lebih egaliter, demokratis dan membasiskan penghargaan sosial berdasarkan merit system (pendidikan, keahlian, peran sosial dst).

Bahasa Sasak adalah bahasa yang dipakai oleh suku Sasak. Kampung halamanannya adalah Pulau Lombok. Diperkirakan (data Tahun 2010), penutur asli bahasa ini berjumlah sekitar 2.7 juta. ${ }^{16}$ Bahasa Sasak lebih banyak dipakai sebagai bahasa lisan ketimbang tulisan. Dialeknya terbagi menjadi lima, yaitu: dialek kuto-kutè (utara), nggeto-nggetè (tenggara), menomenè (tengah), ngeno-ngenè (tengah timur, tengah barat) dan meriaq-meriku (tengah selatan). ${ }^{17}$

Bahasa Sasak mengenal tingkatan-tingakatan bahasa mulai dari bahasa jamaq, tengaq dan alus. Bahasa halus biasanya digunakan dalam konteks formal sebagai bahasa pengantar dimana orang yang dihormati (menak, bangsawan) terlibat. ${ }^{18}$ Tingkatan-tingkatan bahasa ini, menurut penelitian Peter K. Austin, bukanlah fenomena asli Sasak, tetapi pinjaman dari Bali dan Jawa. Austin -dengan mengutip Nothofer-menulis bahwa tingkatan-tingkatan bahasa dalam

14 Ibid., h. 33-34.

15 http://www.wacana.co/2010/07/sejarah-dan-tradisi-suku-sasak/, diakses Tanggal 5 Nov 2017, Jam 20.30 WITA.

16 https:/ / en.wikipedia.org/wiki/Sasak_language, diakses Tanggal 6 Nov 2017, Jam 11.00 WITA.

17 Sudirman Wilaian. Pemertahanan Bahasa dan Kestabilan Kedwibahasaan Pada Penutur Bahasa Sasak di Lombok. Jurnal Linguistik Indonesia, Tahun ke-28, No 1, Februari 2010 (23-39), h. 24-25.

18 Sri Wahyuningsih dkk. Polite Language Maintenance Among Members of Sasak Noble Families in Mataram. The Indonesian Journal of Language and Language Teaching, Vol 1, No 2, Mei 2016. 
Bahasa Sasak, "lend further support to the bypothesis that this system is not a Sasak creation but a borrowing phenomenon"". ${ }^{19}$

Kini, baik sebagai bahasa lisan atau tulisan, bahasa Sasak semakin jarang dipakai sebagai satu-satunya bahasa dalam komunikasi orang Sasak. Di kota, bahkan di desa, bahasa Indonesia lebih mendominasi sebagai bahasa komunikasi. Media-media yang beredar di gumi Sasak juga sepenuhnya menggunakan bahasa Indonesia. Diperlukan strategi jitu agar bahasa Sasak kembali menjadi bahasa arus utama yang beredar di pulau Lombok. Jika tidak, bahasa ini akan terus menerus tergerus dan punah sebagaimana nasib banyak bahasa lokal di dunia.

Salah satu ciri khas orang Indonesia adalah jiwa seninya. ${ }^{20}$ Orang Sasak rupanya tidak keluar dari gambaran ini. Masyarakat Sasak adalah masyarakat yang senang berkesian. Kesenian Sasak bisa ditemukan dimana-mana: di seni musik, seni lukis, seni pertunjukan, seni ukir dan lain-lain.

Yang paling sering muncul adalah pertunjukan-pertunjukan "kesenian jalanan" yang orang Sasak menamakannya kecimol, oncer, ale-ale, gendang beleq dan yang biasanya muncul di acara-acara ngiring penganten pada peristiwa nyongkolan.

Pada zaman dahulu, di banyak tempat di pulau Lombok begawe/pesta pernikahan bisa sampai memakan waktu berhari-hari. Pada malam hari, biasanya kesenian rakyat akan ditampilkan, mulai dari pementasan sandiwara, pertunjukan wayang dan pentas musik. Hingga hari ini, banyak orang Sasak rela mengeluarkan banyak uang untuk begawe ketika anak mereka merariq/menikah meskipun memaksakan diri dengan berhutang karena kondisi ekonomi yang tidak imbang dengan keinginan untuk begawe beleq (pesta besar).

Inilah paradoks antara kemiskinan di satu sisi dan jor-joran begawe/pesta di sisi lain. Kesenian yang membalut keperihan (kemiskinan) inilah yang menjadi salah satu ciri khas lagu-lagu Sasak. Pangkat Ali menulis, "Jika ditelusuri dari cara berkesenian, khususnya seni suara, pekat sekali terpancar nuansa pilu. Selain mengambil lirik melankolis (tentang kepedihan hidup), tembang-tembang Sasak banyak melantunkan cinta (seperti suka dukanya bercinta), cinta pertama, patah hati, atau spirit hidup tanpa cinta...". ${ }^{21}$

Tetapi itulah jiwa seni. Ia bisa mengasyiki kebahagiaan tetapi juga kepiluan dan penderitaan. Jiwa seni orang Sasak ini juga terwujud pada ukiran, tenunan yang proses pembuatannya disebut nyengsek, arsitektur bangunan/rumah adat, dan lain-lain. Inilah sisi indahnya jiwa seni itu. Apapun yang disentuhnya bisa menampilkan keindahan, sebagaimana landscape Pulau Lombok yang seolah "lukisan" Tuhan yang dihamparkan di gumi Sasak.

${ }_{19}$ Peter K. Austin, Documenting Endangered Literaty Genres in Sasak, Eastern Indonesia. Australia: ANDC., h. 5.

${ }^{20} \mathrm{http}: / /$ nationalgeographic.co.id/berita/2016/08/pidato-kebudayaan-mochtar-lubis-menguak-enamsifat-manusia-indonesia, diakses Tanggal 6 Nov 2017, Jam 16.30 WITA.

${ }^{21}$ http:/ / budaya.kampung-media.com/2016/12/22/ ciri-ciri-umum-suku-sasak-17069, diakses Tanggal 6 Nov 2017, Jam 20.30 WITA. 
Sebagaimana tergambar dalam sejarah, kekuasaan di Lombok dipegang oleh raja-raja, apakah raja-raja itu genuin dari suku Sasak atau outsiders yang datang menaklukan kekuasaan raja-raja Sasak. Kedekatan dan kooperasi dengan raja-raja penguasa ini melahirkan reward berupa gelar kebangsawanan atau aset-kekayaan. Dalam banyak narasi sejarah, para bangsawan suku Sasak pun kemudian lebih sering berpihak kepada penguasa daripada rakyat kebanyakan. Yang paling menyakitkan adalah ketika para bangsawan Sasak ini bermufakat jahat dengan penjajah untuk mengangkangi rakyat suku bangsa Sasak sendiri. ${ }^{22}$

Karya-karya novel berkonteks sejarah-nya Salman Faris misalnya adalah narasi tentang bagaimana tokoh Sasak yang bervisi humanis, egaliter, pluralis (seperti tokoh Guru Dane) berjuang-memberontak dengan taruhan mati syahid untuk membebaskan rakyat bangsa Sasak dari penjajahan -terutama dalam hal ini, konteksnya adalah kekuasaan raja-raja Bali dan penjajah Belanda di Lombok--. Dalam konteks berhadap-hadapan seperti ini, yang juga dihadapi oleh para pejuang Sasak ini adalah anak suku bangsanya sendiri yang menjadi pesuruh/sekutu para penguasa. ${ }^{23}$

Sementara itu, ketika banyak kalangan bangsawan Sasak lebih dekat/berpihak dengan pihak penguasa/penjajah, komando perjuangan rakyat Sasak diambil alih oleh para tuan guru. Ketika para bangsawan Sasak menjadi bagian dari struktur pemerintahan Belanda, Tuan Guru mengambil peran sebagai pemimpin sosial-politik rakyat Sasak. ${ }^{24}$

\section{Pengetahuan dan Perilaku dalam Masyarakat Sasak}

Kalau boleh disimplifikasi, Sasak adalah sama dengan Islam plus adat. Meskipun di ujung utara Pulau Lombok pernah dan masih ada varian Islam yang disebut "Islam Wetu Telu" tetapi sebagian besar masyarakat Sasak adalah seratus persen muslim. Jika ada pandangan strereotype tetang pengikut "Islam Wetu Telu" di daerah Bayan dan sekitarnya, tetapi ada dua hal dari persepektif lain yang mesti dipertimbangkan: pertama, bahwa Islam Wetu Telu bukanlah agama yang menyempal dari Islam, tetapi penerapan Islam yang ditubuhkan pada peristiwa dan pranata adat; kedua, jika tesis bahwa orang Sasak = Islam + adat, maka mempraktikkan Islam dengan cara Bayan adalah pembuktian par exellence dari tesis ini.

Karena menurut salah satu versi adalah bahwa dari awal mula penyebaran Islam -secara literatur, versi ini yang disebut lebih awal-terjadi tidak melalui expedisi militer tetapi perjalanan dakwah dari seorang dan kemudian beberapa orang ulama, seperti Syekh

22 http://www.sasak.org/2010/11/van-der-kraan-dan-menak-bangsawan-sasak/, diakses Tanggal 7 Nov 2017, Jam 06.10 WITA.

23 http://rensingbatdesa.blogspot.co.id/2011/10/salman-faris-penulis-novel-guru-dane.html, diakses Tanggal 7 Nov 2017, Jam 17.00 WITA.

${ }^{24}$ Jeremy Kingsley. Tuan Guru, community and conflict in Lombok, Indonesia (Dissertation). Melbourne: Melbourne Law School The University of Melbourne, 2010. H. 94-95. 
Abdurrazzaq al-Gauts yang diklaim makamnya masih berada di komplek Masjid Kuno Bayan dan murid-murid beliau, maka proses islamisasi di gumi Sasak terjadi secara smooth tanpa benturan dengan pranata adat/tradisi dan sosial yang sudah lebih dahulu eksis di gumi paer Sasak.

Ketika kemudian Kerajaan Selaparang sebagai kerajaan besar yang pernah eksis di Lombok menjadi muslim/Islam, maka proses integrasi Islam dengan adat berjalan semakin sistematis-massif-terencana. Itulah yang masyarakat muslim Sasak warisi hingga hingga hari ini. Dimulai dari akar makna kata Sasak misalnya, sudah terpatri ajaran tauhid di situ. Sasak menurut Anggrat Idrus berasal dari sa' sa' yang berarti yang satu, yang esa. Orang Sasak muslim sepenuhnya mengacu dalam pengetahuan dan perilaku kepada "Yang Satu, Yang Esa" ini.

Ajaran pokok, inti dan berada di hulu ini kemudian meng-hilir ke aturan-aturan adat yang lebih rinci dan implementatif-mengikat. Aturan adat soal sorong serah aji krame misalnya, merupakan pengejawantahan dari ajaran-ajaran Islam. Aji krame, harga diri (adat) 33 melambangkan wirid setelah shalat yang masing-masing diulang-ulang sebanyak 33 kali; aji 66 adalah penjumlahan dari 33 yang pertama plus sifat-sifat Allah dan sifat-sifat Rasululllah Muhammad SAW; sedangkan aji 100 adalah perlambang dari 99 nama-nama Allah yang terbaik (al-asma' al-husna) plus taubid, Allah yang esa. ${ }^{25}$

Secara sosial, hidup lurus adalah filosofi hidup yang paling inti pada masyarakat Sasak. Inilah makna filsafat hidup yang digali dari kata Lombok (baca: lumbu') yang berarti lurus. Dalam perspektif Islam, ini adalah, as-Shirath al-Mustaqim, jalan yang lurus. Pandangan dan nilai filosofis ini menurut filsafat hidup yang lebih operasional pada orang Sasak, yaitu tindih, maliq dan merang.

Tindih, kurang lebih, bermakna kejujuran, satunya kata dan perbuatan. Jujur juga bermakna hati-hati dalam membuat pilihan; berusaha selalu mencari yang benar dalam ungkapan dan tindakan; tidak neko-neko dan teguh berpegang pada prinsip dalam hubungan sosial-kemasyarakatan. Jika sudah dikhianati, orang Sasak tidak akan percaya sampai mati; tetapi begitu percaya dengan orang lain, ia akan bela sampai mati juga -kadang-kadang tanpa peduli apakah orang yang dipercayainya itu benar atau salah.

Maliq, kurang lebih, maknanya adalah pantang, tidak elok (bukan hanya tidak boleh), kata orang sunda; pamali atau haraj dalam Bahasa Arab. Sejatinya orang Sasak pantang berbuat hal-hal yang bertentangan dengan bukan hanya aturan yang tegas dalam agama tetapi juga yang bertentangan dengan adab, tata krama atau etiket dalam agama. Contoh kecil saja, ketika rowah (tasyakuran atau selamatan) dan kemudian makan bersama, para jamaah akan pantang 
membasuh tangan duluan sebelum tuan guru, kyai atau orang yang dihormati membasuh tangannya.

Merang, lebih kurang, artinya adalah tajam. Kiasan atau tamsil ini diambil dari senjata tajam. Senjata tajam akan mudah digunakan untuk segala tujuan jika terus diasah dan dijaga ketajamannya. Artinya dalam kehidupan sosial, orang Sasak selalu berusaha untuk berguna bagi orang lain. Jika ada yang kepaten (anggota keluarganya meninggal dunia), tanpa diminta tetangganya akan membantu. Demikian juga kalau ada hajat yang memerlukan bantuan orang lain. Ke-guyub-an dan ketuntasan melaksanakan pekerjaan akan sangat terasa dengan pengaplikasian nilai merang ini. Lebih dari itu, filosofi merang menuntut inovasi dalam pekerjaan, baik dari segi kuantitas maupun kualitasnya.

\section{Penutup}

Inti identitas orang Sasak adalah gabungan antara agama (Islam) dan adat. Adat dipahami sebagai pengejawantahan dari ajaran agama. Formasi ini terbentuk oleh sejarah, tanah air, model produksi, struktur sosial, bahasa, seni dan politik-kekuasaan. Bauran berbagai unsur tadi membentuk formasi pengetahuan yang tipikal pada masyarakat Sasak. Mekanisme mengalir dari agama sebagai hulu dari segala pengetahuan, kemudian diturunkan ke pranata budaya dan diartikulasikan pada tulisan atau ucapan yang menjadi acuan perilaku orang Sasak kebanyakan. Inti perilaku itu adalah lurus (lomboq)-nya ucapan dan tindakan yang diturunkan pada berbagai perilaku spesifik yang memelihara keharmonisan hubungan antara manusia dengan Tuhan, alam dan sesama.

\section{Daftar Pustaka}

al-Jabiri, Mohamed Abid. Takwin al-Aql al-Arabi. Beirut: Markaz Dirasat al-Wahdah alArabiyah, 2009.

Asnawi. "Respons Kultural Masyarakat Sasak Terhadap Islam.” Ulumuna 9, no. 1, JanuariJuni 2005).

Austin, Peter K. Issues in the Creation of Trilingual Dictionary for Sasak, Eastern Indonesia. University of London, ICLDC Workshop, Feb 2011. - Aksara Sasak, an Endangered Script and Scribal Practice, London: University of London, SOAS, 2014. . Documenting Endangered Literaty Genres in Sasak, Eastern Indonesia. Australia: ANDC. . Reading the Lontars: Endangered Literature of Lombok, Eastern Indonesia. London: University of London, SOAS, 2014 
Aziz, Ahmad Amir. "Islam Sasak: Pola Keberagamaan Komunitas Islam Lokal di Lombok." Millab: Jurnal Studi Agama 8, no. 2 (2009): 241-253. http://journal.uii.ac.id/Millah/article/view/5230.

Ba'albakki, Ahmad dkk. al-Huwiyyah wa Qadlayaha fi al-Wa'y al-'Arabi al-Mu'ashir. Beirut: Markaz Dirasat al-Wahdah al-Arabiyah, 2013.

Bafadhal, Fadjal AR dan Asep Saefullah. Naskah Klasike Keagamaan Nusantara Cerminan Budaya Bangsa 1. Jakarta: Puslitbang Lektur Keagamaan Departemen Agama RI, 2005.

Budiwanti, Erni. Islam Sasak: Waktu Telu Vs Waktu Lima. Yogyakarta: LKiS, 2000.

Fahrurrozi. "Dakwah Tuan Guru dan Transformasi Sosial di Lombok Nusa Tenggara Barat." Disertasi, Sekolah Pascasarjana UIN Syarif Hidayatullah Jakarta, 2010.

Foucoult, Michel. The Archaeology of Knowledge, terj. A.M. Sheridan Smith. New York: Pantheon Book, 1971.

Friedman, Thomas L. The World is Flat: A Brief History of $21^{\text {st }}$ Century. New York: Farrar, Strous and Giroux, 2005.

Hanafi, Hassan. Al-Hwwiyyah. Cairo: al-Majlis al-A'la li ats-Tsaqafah, 2012.

Hidayat, Toni Syamsul. "Bahasa Sasak Halus dan Perilaku Sosial Masyarakat Penuturnya." Seminar Nasional Pemertahanan Bahasa Nusantara. Magister Linguistik PPs UNDIP Semarang, 6 Mei 2010.

Khalil, Imaduddin. At-Tafsir al-Islami li at-Tarikh. Beirut: Dar al-Ilmi li al-Malayin, 1981.

Kingsley, Jeremy Jacob. "Tuan Guru Community and Conflict in Lombok Indonesia.” PhD Thesis, The University of Melbourne, 2010.

Klock, John. Historical Hydrologic Landscape Modification and Human Adaptation in Central Lombok Indonesia from 1894 to the Present. Geo 522. Maret 2008.

Kontjaraningrat. Kebudayaan, Mentalitas dan Pembangunan. Jakarta: Gramedia, 1994.

Kumbara, A. A. Ngr Anom. "Konstruksi Identitas Orang Sasak di Lombok Timur, Nusa Tenggara Barat.” Humaniora 20, no. 3 (Oktober, 2008): 315-326. https://jurnal.ugm.ac.id/jurnal-humaniora/article/view/947.

Lukman, L.H. Pulau Lombok dalam Sejarah. Lombok: Cerdas Press, 2005. - Bahasa dan Relasi Sosial: Telaah Kesepadanan Adaptasi Lingustik dengan Adaptasi Sosial. Yogyakarta: Gama Media, 2006.

Mahsun. Kajian Dialektologi Diakronis Bahasa Sasak di Pulau Lombok. Yogyakarta: Gama Media, 2006.

Mahyuni. "Valuing Language and Culture: an Example from Sasak." Makara Human Behavior Studies in Asia 11, no. 2 (2007): 79-86. http://hubsasia.ui.ac.id/article/view/257.

Mahyuni. Speech Style and Cultural Consciousness in Sasak Community. Lombok: Cerdas Press, 2006.

Marrison, Geoffrey E. Sasake and Javanese Literature of Lombok. Leiden: KITLV Press, 1999. 
Mucchielli, Alex. Al-Humiyyah, terj. Ali Wathfah. Damaskus: Dar an-Nasyr al-Faransiyyah, 1993.

Mulyadi, L. Sejarah Gumi Sasak Lombok. Malang: ITN, 2014.

Sabirin. "Konfigurasi Pemikiran Islam Tuan Guru: Respon Pemikiran Tuan Guru Terhadap Penetrasi Ajaran Wahabi pada Etnik Sasak di Pulau Lombok 1993-2007." Tesis, Program Pascasarjana UI, 2008.

Sudirman Wilaian. Pemertahanan Bahasa dan Kestabilan Kedwibahasaan Pada Penutur Bahasa Sasak di Lombok. Jurnal Linguistik Indonesia 28, no 1, Februari 2010 (23-41). https: / / lib.atmajaya.ac.id / default.aspx?tabID=61\&id=168015\&src $=1$

Syahdan. "Sasak-Indonesian Code Switching." Dissertation, University of Arizona, 1996.

Tharabsyi, George. Nazhariyt al-Aql. London: Dar as-Saqi, 1999.

Thoyyib, L. Ibrahim M. Wajab Lombok Zaman Dabulu. Jakarta: Tunas Ilmu, 2010. - Jejak Dakwah Para Wali. Jakarta: Tunas Ilmu, 2010.

Wahyuningsih, Sri. "Polite Language Maintenance Among Members of Sasak Noble Families In Mataram." The Indonesian Journal of Language and Language Teaching 1, no. 2 (2016): 4452. http://ijolt.unram.ac.id/index.php/ijolt/article/view/17. 